Article

\title{
Prediction of the Load-Bearing Behavior of SPSW with Rectangular Opening by RBF Network
}

\author{
Mohammad Javad Moradi ${ }^{1}$ (i), Mohammad Mahdi Roshani ${ }^{2}$, Amirhosein Shabani ${ }^{3, *}$ (i) and \\ Mahdi Kioumarsi ${ }^{3}$ \\ 1 Department of Civil Engineering, Razi University, Kermanshah 67144-14971, Iran; \\ m.j.moradi1988@gmail.com \\ 2 Young Researchers and Elite Club, Islamic Azad University, Kermanshah Branch, Kermanshah 67189-97551, \\ Iran; m.roshani69@yahoo.com \\ 3 Department of Civil Engineering and Energy Technology Civil Engineering, Oslo Metropolitan University, \\ 0167 Oslo, Norway; mahdik@oslomet.no \\ * Correspondence: amirhose@oslomet.no; Tel.: +47-96759302
}

Received: 26 December 2019; Accepted: 5 February 2020; Published: 10 February 2020

check for updates

\begin{abstract}
As a lateral load-bearing system, the steel plate shear wall (SPSW) is utilized in different structural systems that are susceptible to seismic risk and because of functional reasons SPSWs may need openings. In this research, the effects of rectangular openings on the lateral load-bearing behavior of the steel shear walls by the finite element method (FEM) is investigated. The results of the FEM are used for the prediction of SPSW behavior using the artificial neural network (ANN). The radial basis function (RBF) network is used to model the effects of the rectangular opening in the SPSW with different plate thicknesses. The results showed that the opening leads to reduced load-bearing capacity, stiffness and absorbed energy, which can be precisely predicted by employing RBF network model. Besides, the suitable relative area of the opening is determined.
\end{abstract}

Keywords: artificial neural network; steel shear wall; finite element method; opening; radial basis function

\section{Introduction}

Walls have been utilized in construction not only as a barrier (i.e., basement walls) [1,2] or infill (i.e., infill masonry walls) [3,4] but also as a lateral load-bearing system. The steel plate shear wall (SPSW) is considered as a lateral load resisting system which is not only used as a load-bearing system for designing new buildings but also is employed as a retrofitting technique for existing structures. The application of this system compared to reinforced concrete shear wall (RCSW) system has increased in the past few decades, due to some advantages, such as lower weight, cost-effectiveness, and proper performance [5], which make some designing codes to add it as a suitable lateral load-bearing system [6,7]. SPSW diminished the amount of steel in the construction of new buildings and it is lighter than the RCSW system [8,9]. Moreover, as a retrofitting technique, SPSW can be easily installed in critical parts of the buildings $[10,11]$. Some full-scale studies have been done to evaluate the performance of different types of structures equipped with SPSWs [12-16], but more investigations are needed at substructure level for assessment of the exact behavior of SPSWs with different configurations.

SPSWs are required to be very thin in thickness, according to the design phase, especially in upper stories. Preparing very thin plates and installing them is not practical and in this situation, a thicker plate with an opening is recommended [17,18]. Moreover, because of necessary architectural or functional issues, openings and their effects need to be considered in SPSW systems. 
Although experimental and numerical researches have been done to investigate the lateral load-bearing behavior of the SPSW with different shapes of opening and different areas, more studies are required to investigate this issue's effects [9,17,19-30]. A short description about the previous researches are presented in Table 1. Besides, evaluation of the shear wall behavior with circular opening is done using Multi-Layer Perceptron (MLP) by Khalilzadeh Vahidi and Roshani [29], and developing the artificial neural network (ANN) model using experimental SPSW database is conducted by Moradi and Hariri-Ardebili [5]. The suitable performance of the machine learning procedures in estimation of the structural behavior has been proven [31-36].

The significant advantages of these methods, such as high accuracy, less time-consuming, and also no need for expertise in special software and codes, lead to the transformation from traditional finite element method (FEM) or expensive experimental tests to utilizing machine learning for prediction of the behavior of the substructures. It can be predicted that in near future machine learning methods substitute traditional equation methods for designing buildings. Although, ANN has some disadvantages that limit its application in some areas of structural engineering. One of the main disadvantages of ANN is that the accuracy of the network depends on the number of the samples, also it takes a long time to find out the best architecture and network parameters [37,38].

Table 1. A summary of the researches about the effects of openings on steel plate shear walls (SPSWs).

\begin{tabular}{|c|c|c|c|c|c|c|}
\hline Name & Year & No. Sample & Investigated Parameters & No. Story & Type of Research & Ref. \\
\hline Takahashi & 1973 & 12 & SPSW with opening and without opening & 1 & Experimental & [19] \\
\hline Deylami and Daftari & 2000 & 50 & Plate thickness, opening aspect ratio and opening percentage & 1 & Analytical & [21] \\
\hline Vian and Bruneau & 2004 & 2 & Opening & 1 & Experimental & [22] \\
\hline Pellegrino et al. & 2009 & N.A. & Dimension, position shape and, orientation & 1 & Analytical & [23] \\
\hline Valizadeh et al. & 2012 & 8 & Opening dimensions and slenderness factors & 1 & Experimental & [25] \\
\hline Sabouri-Ghomi et al. & 2012 & 45 & Opening dimensions and shapes & 1 & Analytical & [9] \\
\hline Sabouri et al. & 2015 & 4 & Behavior of SPSW with 2 openings & 1 & Experimental & [39] \\
\hline Khalilzadeh and Roshani & 2016 & 54 & Opening Location, Infill plate and, Stiffener Thickness & 1 & Analytical & [29] \\
\hline Nassernia and Showkati & 2017 & 3 & Opening Diameter in mid-span SPSW & 1 & Experimental and Analytical & [30] \\
\hline Afshari and Gholhaki & 2018 & N.A. & Opening Shape, Diameter, Location and $\mathrm{H} / \mathrm{b}$ ratio of SPSW & 1 & Analytical & [17] \\
\hline
\end{tabular}

The purpose of this study is to evaluate the effects of the rectangular openings on lateral behavior of SPSWs using teh radial basis function (RBF) approach. Finite element models are developed and verified by experimental results. The thickness of the steel plate and area of the opening is changed to develop rich numerical data. Changes in load-bearing capacity, stiffness, and energy absorption are also determined by changing the area of the opening. RBF is an efficient computational method is proposed to estimate the load-bearing capacity, stiffness, and energy dissipation of the SPSW. Using a neural network, one can estimate the behavior of an SPSW with a rectangular opening and determine the parameters affecting the wall's behavior. The proposed network can be used to design the new walls or retrofit the existing ones with high accuracy with less time and need to expert in any special software packages.

\section{Finite Element Modeling (FEM)}

In order to evaluate the effect of opening on the behavior of SPSWs, 110 SPSW archetypes are modeled using ABAQUS 6.14 (Dassault, Paris, France) software [40]. Software verification is done to ensure the accuracy of responses using the Alavi and Nateghi experimental test [26]. In the experimental study, two models have been studied in a way that the first model is without any opening (SPSW2) and the other one is with an opening in the middle of the shear wall (SPSW s4). In Figure 1a,b experimental samples that are utilized for the verification of finite element models are shown. Fishplate connects the infill plate to the boundary elements which is not modeled. It is illustrated in [12], that the absence of the fish plate in finite element models does affect the results. The exact dimension of the SPSW of the experiments and the finite element models are illustrated in Figure 1b. Mechanical properties of steel material used in this modeling are listed in Table 2. 


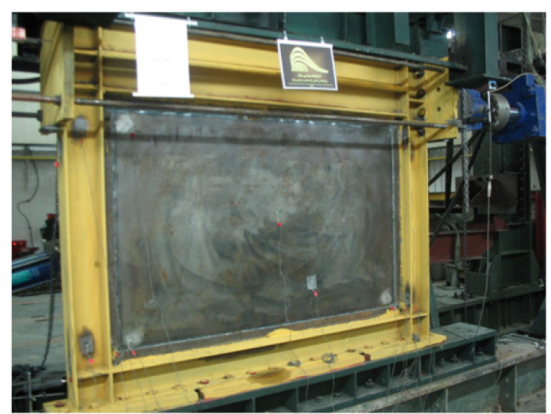

(a)

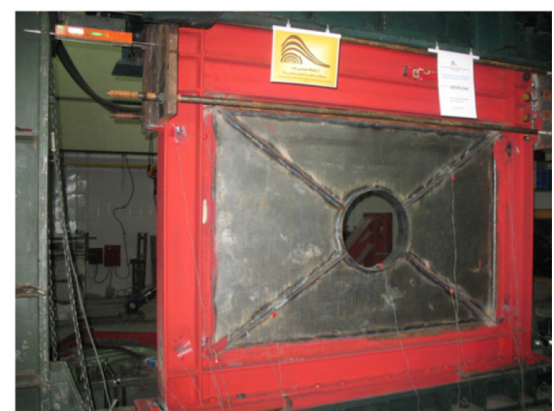

(b)

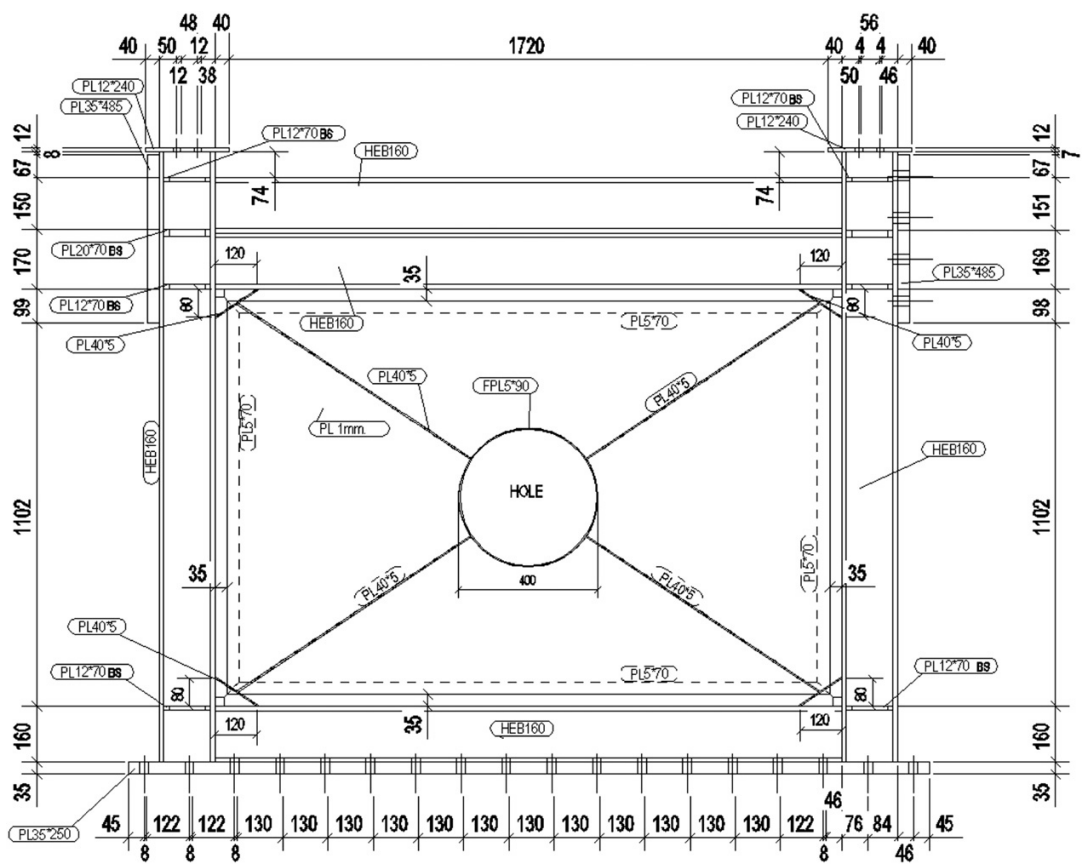

(c)

Figure 1. Experimental specimens which are using to verify Abaqus software [26] (a) SPSW2, and (b) SPSW s4 models, (c) dimension details of the SPSW s4 model.

Table 2. Mechanical properties of steel material used in modeling [26].

\begin{tabular}{cccccc}
\hline Element & $\mathbf{E}(\mathbf{M P a})$ & $\mathbf{F}_{\boldsymbol{y}} \mathbf{( M P a )}$ & $\left.\mathbf{F}_{\boldsymbol{u}} \mathbf{( M P a}\right)$ & $\epsilon_{\boldsymbol{y}}(\mathbf{\%})$ & $\boldsymbol{\epsilon}_{\boldsymbol{u}}(\mathbf{\%})$ \\
\hline HEB 160 (SPSW s4) & $2.06 \times 10^{5}$ & 340 & 450 & 0.17 & 14.4 \\
HEB 160 (SPSW2) & $2.07 \times 10^{5}$ & 400 & 450 & 0.19 & 13.2 \\
The stiffener plate $(\mathrm{t}=5 \mathrm{~mm})$ & $2.05 \times 10^{5}$ & 340 & 470 & 0.17 & 20.5 \\
The infill plate $(\mathrm{t}=1 \mathrm{~mm})$ & $2.04 \times 10^{5}$ & 280 & 500 & 0.14 & 21.6 \\
\hline
\end{tabular}

In Figure 2, the load-displacement diagrams of the experimental and numerical specimens are presented. As can be seen, the numerical curve has more stiffness than experimental. It can be attributed to the inherent nature of FE analysis which leads to an increase in the stiffness of the elements. Besides, the material properties of the steel are considered to be bilinear isotropic/kinematic hardening model. This type of modeling consists of two components: first, an isotropic hardening component in which the yield surface remains the same shape but expands with increasing stress and defines the evolution of the yield surface size as a function of the equivalent plastic strain and, second, a kinematic hardening component in which the yield surface remains in the same shape and size but is translated in the stress space. Besides, the yield surface is defined by the function, using the von Mises yield criterion. There is good agreement between the experimental data and numerical result and the differences can be related 
to some assumptions such as material modeling, merging the boundary elements with the infill plate, and ideal boundary conditions. Figure 3 shows the comparison of experimental SPSW deformations with numerical models. During the experimental testing, the buckling of the plate occurred between the diagonal stiffeners at $0.56 \%$ drift and $353 \mathrm{kN}$ base shear which lead to a reduction of the stiffness of the wall [26]. This can be seen in Figure 2. The residual deformation and local buckling of the experimental and numerical specimens are the same. Mesh sensitivity analysis revealed that the proper mesh size is about $50 \mathrm{~mm}$ where the model has 4824 elements (see Figure 4). The loading is static and pushover applied to the top beam of the finite element frames, and the load-displacement diagram for each model is derived. The maximum load, stiffness and absorbed energy were determined. These values are considered as neural network inputs in the next section.

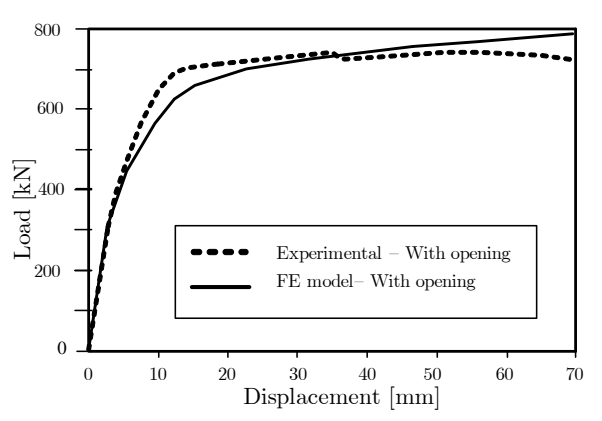

(a)

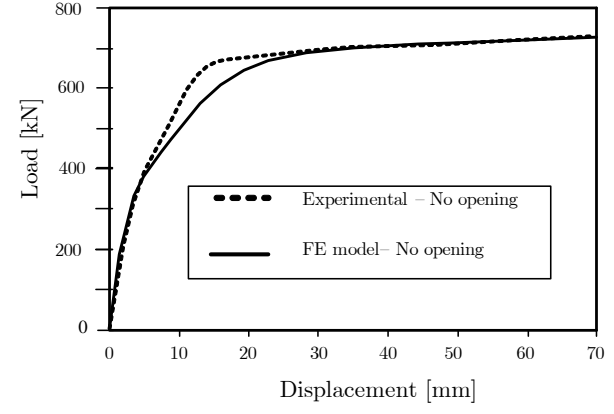

(b)

Figure 2. The load-displacement curves of experimental and numerical models, (a) with opening, and (b) without opening.

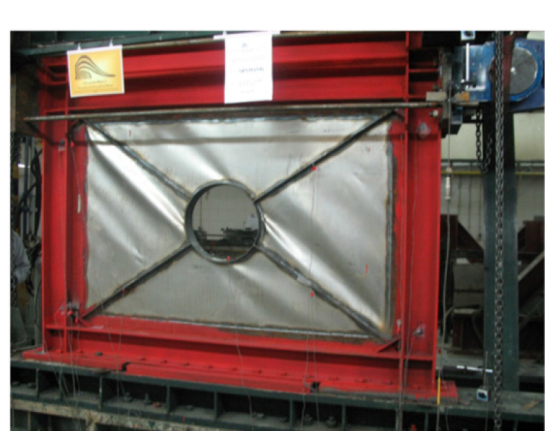

(a)

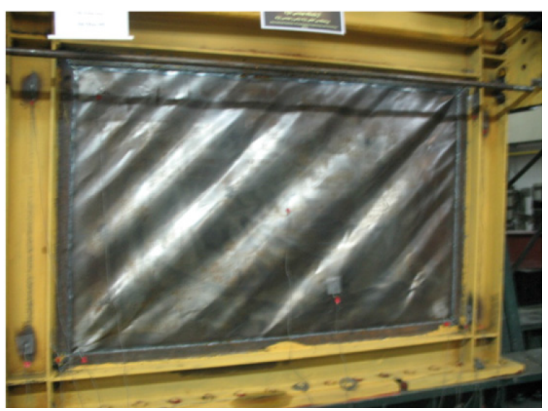

(c)

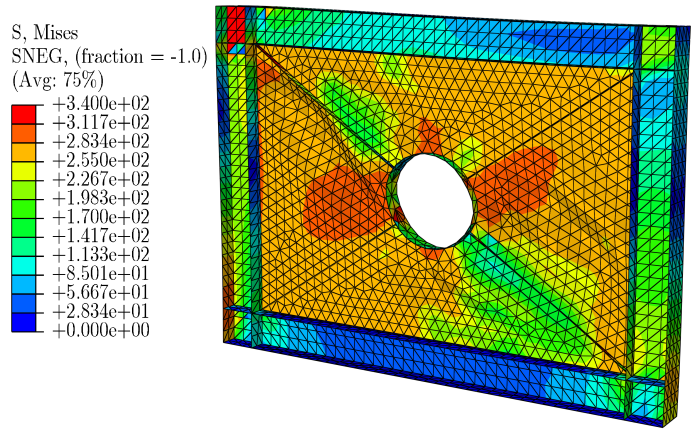

(b)
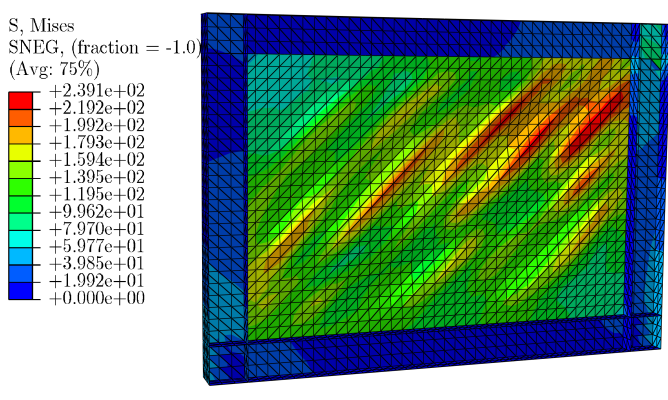

(d)

Figure 3. Comparison of finite element (FE) simulated models and tested specimens at ultimate displacement: (a) deformation in SPSW s4 specimen, (b) von Mises stress distribution and deformation in FE model of SPSW s4, (c) deformation in SPSW2 specimen, (d) von Mises stress distribution and deformation in FE model of SPSW2. 


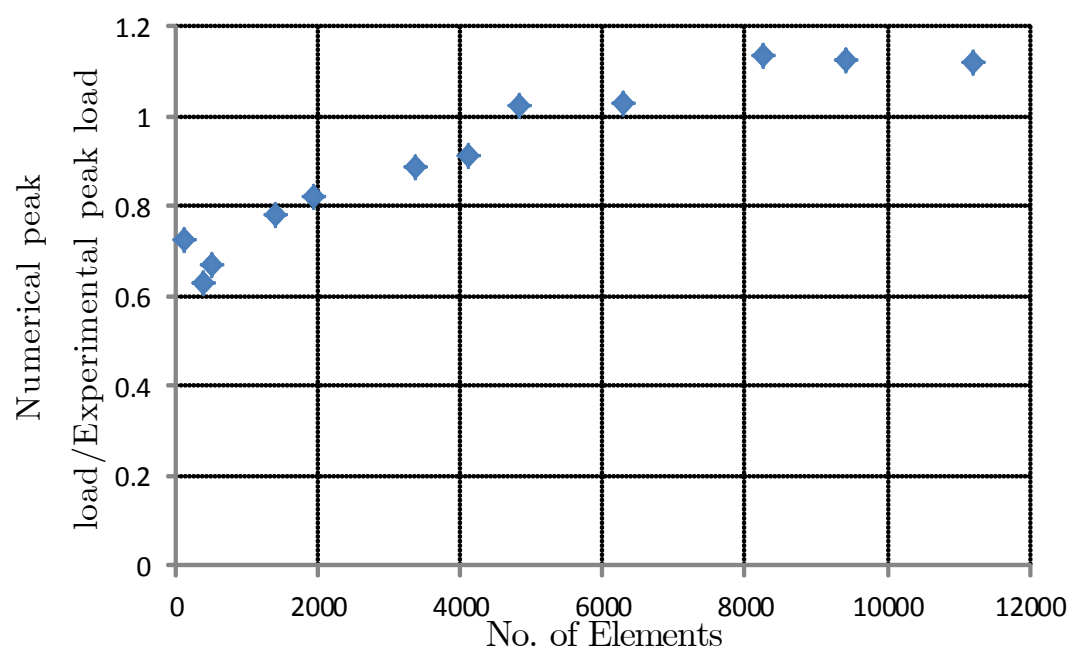

Figure 4. Mesh sensitivity analysis.

For developing the database, finite element models of 110 archetypes with 5 different thicknesses and 22 different dimensions of opening configuration have been simulated in a way that for each thickness of the infill plate, 22 scenarios for opening are investigated (see Table 3). Moreover, openings are considered to be in the central area of the infill plate which was investigated as the critical position by [9]. The dimension of the wall is the same as the verified model as it is shown in Figure 1. It should be mentioned that in entire models the opening is located in the middle of the infill plate. Figure 5 plotted some of the numerical SPSW models. The first digit after the $\mathrm{R}$ indicates the opening width in $\mathrm{mm}$.

Table 3. The range of the evaluated parameters and the number of FEM samples.

\begin{tabular}{ccc}
\hline Parameter & Range & Number of Samples \\
\hline Infill plate thickness $(\mathrm{mm})$ & $0.7,0.8,1,1.2,1.4$ & 5 \\
\hline & No Opening $-200 \times 200-250 \times 250-300 \times 300-350 \times 350-400 \times 400$ \\
Opening area $\left(\mathrm{mm}^{2}\right)$ & $450 \times 450-500 \times 500-550 \times 550-600 \times 600-650 \times 650$ \\
& $700 \times 700-750 \times 750-800 \times 800-850 \times 850-900 \times 900-950 \times 950$ \\
& $1000 \times 1000-1050 \times 1050-1100 \times 1100-1150 \times 1150-1200 \times 1200$ \\
\hline
\end{tabular}

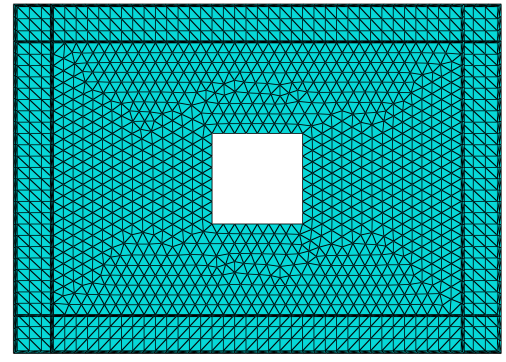

(a)

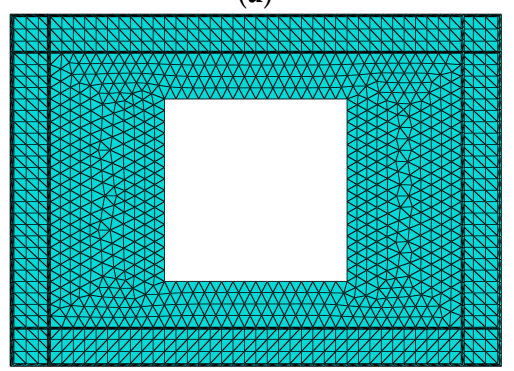

(c)

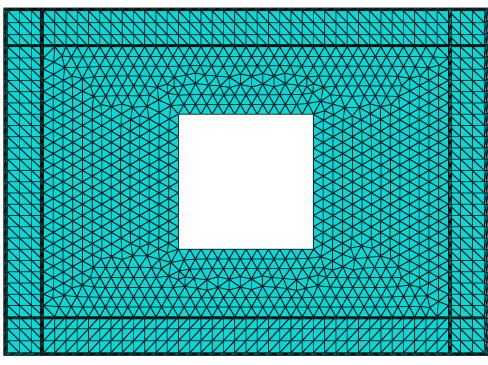

(b)

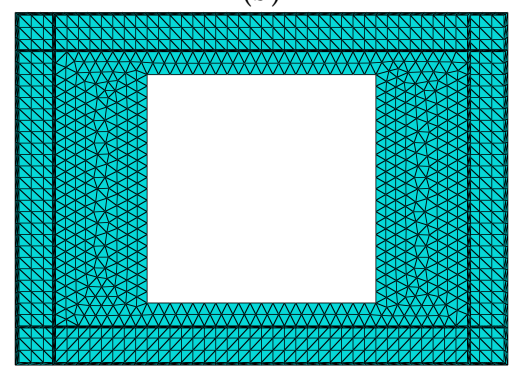

(d)

Figure 5. The numerical model of (a) R400 (b) R600 (c) R800 (d) R1000. 


\section{Neural Network Modeling}

Nowadays, artificial neural networks (ANNs) have been used in several engineering problems for modeling or function approximation applications [41,42]. ANN is used in this paper to model the effects of the rectangular openings in the SPSWs with different plate thicknesses. The RBF is selected for modeling as the neural network.

RBF network is a feedforward network that has one hidden layer and its activation functions are radial basis functions [43]. RBF output is a linear combination of the inputs radial basis functions and neuron parameters. The RBF network structure is similar to the MLP network, but there is one hidden layer in the RBF network. The neurons in the hidden layer of the RBF network are called the RBF centers [44]. The hidden layer outputs are summed in the output layer, as shown in Equation (1).

$$
y=\sum_{i=1}^{n} w_{i} q i
$$

where, $w_{i}$ are the weight values. The neuron outputs in the hidden layer, $q i$, can be written as Equation (2):

$$
q i=\exp \left(-\frac{\left(x_{i}-c_{i}\right)^{2}}{\sigma_{i}^{2}}\right) .
$$

In Equation (2), $X$ is input vector, $C$ is the basis function and $\sigma_{i}$ is the spread of the Gaussian function. Radial basis functions are frequently used to create neural networks for regression-type problems [45].

As mentioned earlier, the rectangular opening effects should be studied in the behavior of the SPSW. In the proposed model, rectangular opening surface to overall SPSW plate surface ratio $\left(\mathrm{A}_{o} / \mathrm{A}_{s}\right)$ and thickness of the SPSW plate, $\mathrm{H}(\mathrm{mm})$, are assumed as the model input parameters. The model output variables are normalized shear strength, $\mathrm{P}$, normalized energy absorption, $\mathrm{E}$ and the normalized stiffness, K. The structure of the proposed ANN model is illustrated in Figure 6.

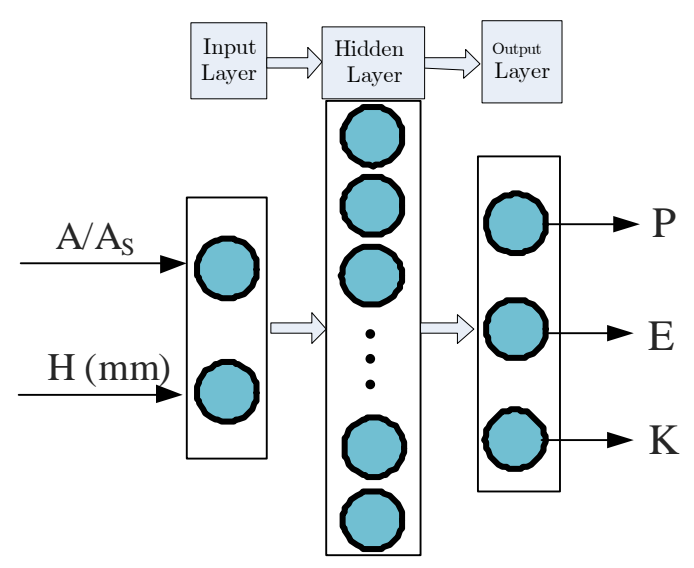

Figure 6. Structure of the proposed radial basis function (RBF) model.

After defining the model parameters, the RBF model specifications should be selected. The neurons number in the output and input layers are considered equal to the number of output and input parameters, respectively. Several RBF models with different specifications were defined to find the best network. The proposed RBF network schematic is shown in Figure 6 and the network specifications are given in Table 4. 
Table 4. Specifications of the proposed RBF model.

\begin{tabular}{cc}
\hline Parameters & Specifications \\
\hline Input parameters & 3 \\
Outputs parameters & 2 \\
hidden layer functions & Radial basis \\
Output layer functions & Linear \\
Maximum number of epochs & 70 \\
Train data number & 77 \\
Test data number & 33 \\
Total data number & 110 \\
\hline
\end{tabular}

The performance of the network evaluated using mean absolute and mean squared errors (MAE and MSE) in this paper, which are defined as follows.

$$
\begin{gathered}
M A E=\frac{\sum_{i=1}^{N}\left|Y_{R i}-Y_{P i}\right|}{N} . \\
M S E=\frac{1}{N} \sum_{i=1}^{N}\left(Y_{R i}-Y_{P i}\right)^{2},
\end{gathered}
$$

where, in these equations, $Y$ is the real value and $N$ is total data number. The $R$ and $P$ indices represent the real and predicted values. 110 shear walls with different rectangular opening sizes and different infill plate thicknesses were modeled and analyzed in this paper, which forms data set for the proposed model. We used 77 data for training the network model and the 33 data are chosen for the testing process of the proposed model. Data are normalized before training to increase the precision of the model.

\section{Results}

The network was trained using the input data and was tested by the remaining data. The regression diagrams, as a tool to evaluate the performance of the network, for the real and predicted values of the proposed model are depicted in Figure 7. As it can be seen, predicted values by RBF network are shown by the circle symbols and the real data are shown by solid lines. According to Figure 7, the proposed model has precisely modeled the rectangular opening effects in the SPSW with different plate thickness. The MSE results of the model output parameters versus the various numbers of epochs are illustrated in Figure 8. As can be seen, the MSE results of the model output parameters decrease with increasing the epochs. In Figure 8, MSE is corresponding to the normalized data values.

As mentioned earlier, the training and testing procedures of the calculated data are performed by the proposed RBF network. The MAE and MSE results of the proposed model for training and testing procedures are listed in Table 5. As mentioned, 110 data were used in the presented model, in which 77 data were considered for training and 33 were assumed for the testing of the model. This data are normalized and randomly selected for test and train. However, the MAE and MSE results in Table 5 are calculated for the denormalized predicted data.

In Figure 9, the real and predicted normalized load (PN) values are compared with different rectangular opening surfaces to the overall SPSW plate surface ratio $\left(\mathrm{A}_{o} / \mathrm{A}_{s}\right)$. As can be seen, an increase in the opening area may lead to a decrease in normalize load-bearing capacity and the rate of decrease is higher for the thicker infill plates. In this figure, predicted values by the RBF network are shown by the star symbols and the real data are shown by the circle symbols and solid lines. 

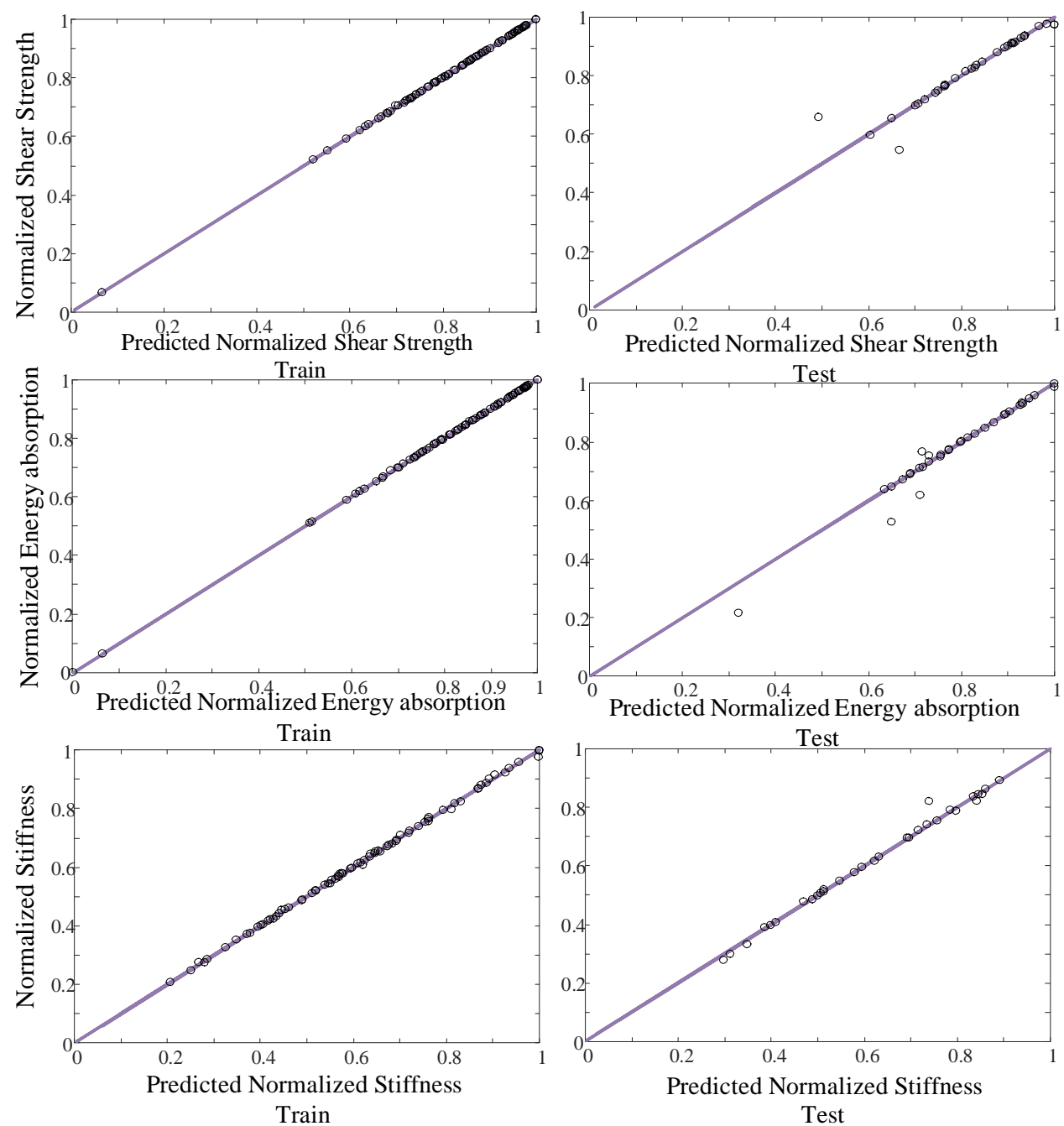

Figure 7. Regression diagrams for the real and predicted values of the proposed model.
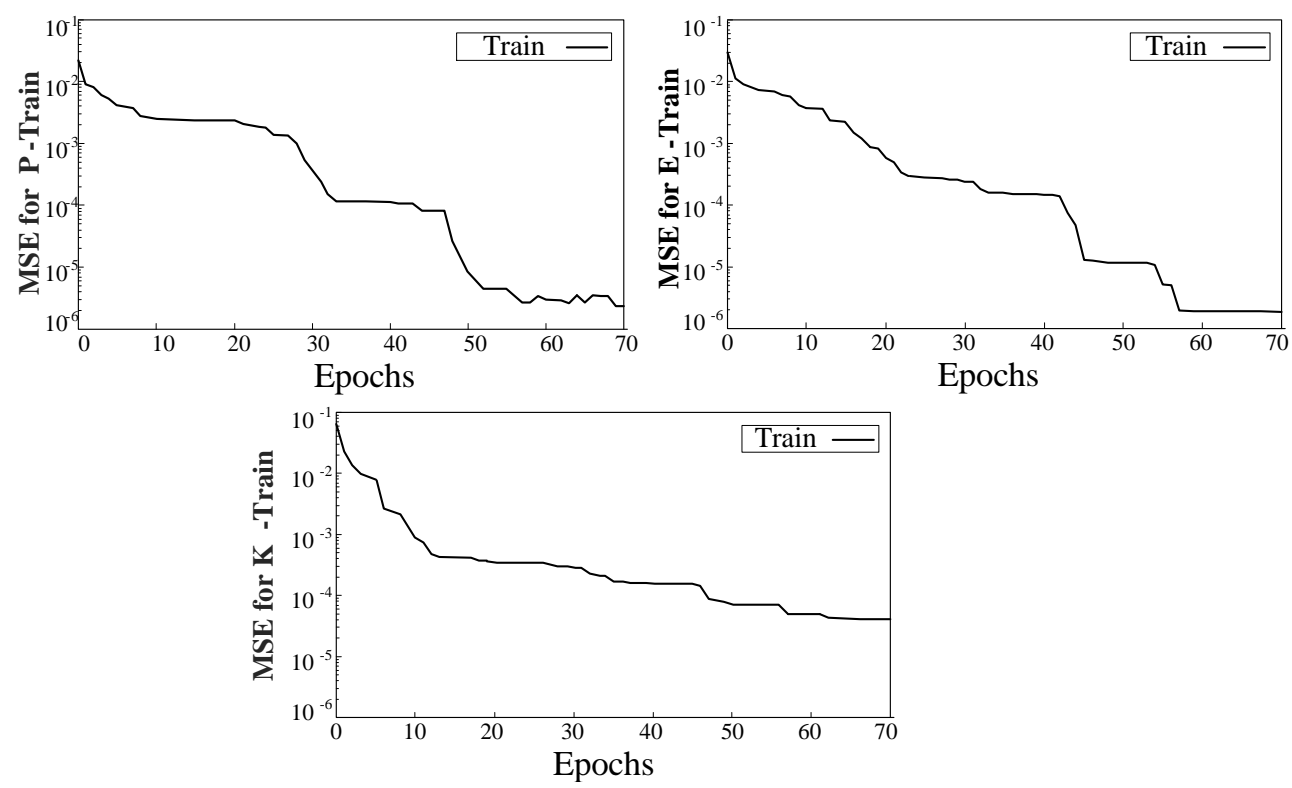

Figure 8. The MSE results of the model output parameters versus different number of epochs. 


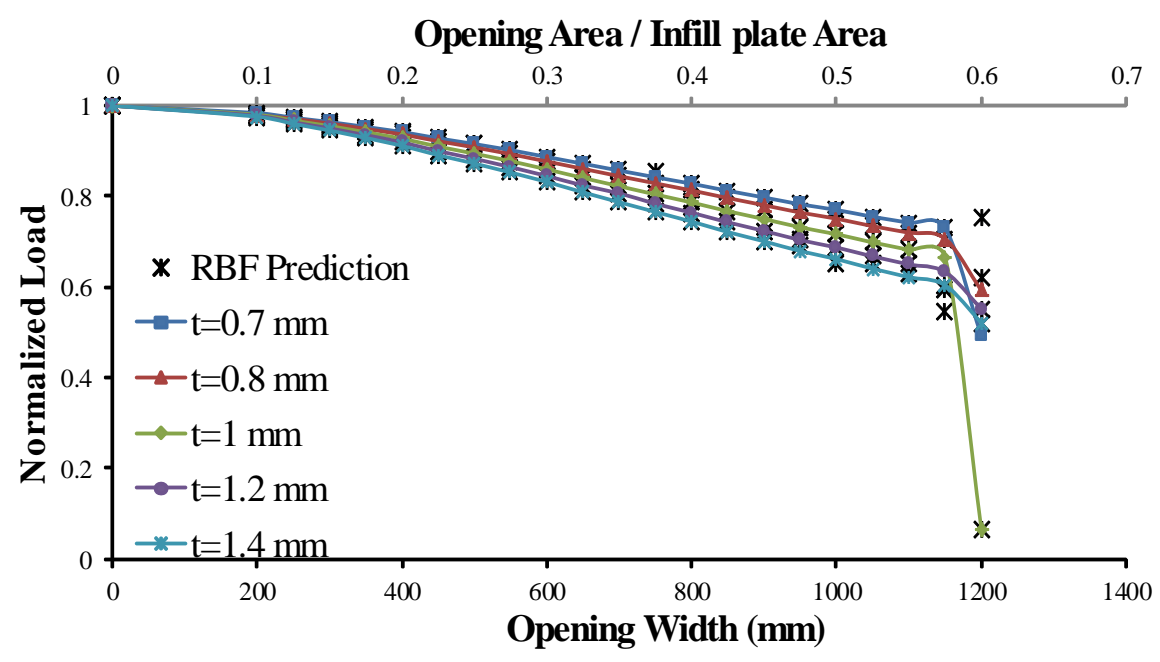

Figure 9. Real and predicted normalized load values versus the various $\mathrm{A}_{o} / \mathrm{A}_{s}$.

Table 5. The mean absolute and mean squared errors (MAE and MSE) results of the proposed model for training and testing procedures.

\begin{tabular}{cccc}
\hline Error values & Normalized Shear Strength & Normalized Energy Absorption & Normalized Stiffness \\
\hline MAE Train & $1 \times 10^{-3}$ & $1.1 \times 10^{-3}$ & $3.5 \times 10^{-3}$ \\
MAE Test & $1.27 \times 10^{-2}$ & $1.38 \times 10^{-2}$ & $7.9 \times 10^{-3}$ \\
MSE Train & $204 \times 10^{-6}$ & $2.08 \times 10^{-6}$ & $2.67 \times 10^{-5}$ \\
MSE Test & $1.3 \times 10^{-3}$ & $1.2 \times 10^{-3}$ & $2.62 \times 10^{-4}$ \\
\hline
\end{tabular}

As a result, it can be said that the creation of rectangular openings in thicker walls results in a major and faster drop in the load capacity, compared to regular steel shear walls. It can also be highlighted that the reduction in the load-bearing capacity is independent of the wall thickness for samples with $\mathrm{A}_{o} / \mathrm{A}_{s}$ up to $15 \%$, where the difference in the maximum and minimum of the load capacity reduction is $2 \%$. Similar results can be obtained for absorbed energy. In the case of shear wall stiffness, the results are similar to those of the load-bearing capacity, but the SPSW stiffness is entirely dependent on the infill plate thickness. Besides, locating an opening leads to reduces shear wall stiffness. The real and predicted normalized energy absorption (EN) and normalized stiffness $(\mathrm{KN})$ values versus different rectangular opening area to overall SPSW plate area ratio $\left(\mathrm{A}_{o} / \mathrm{A}_{s}\right)$ are shown in Figures 10 and 11, respectively.

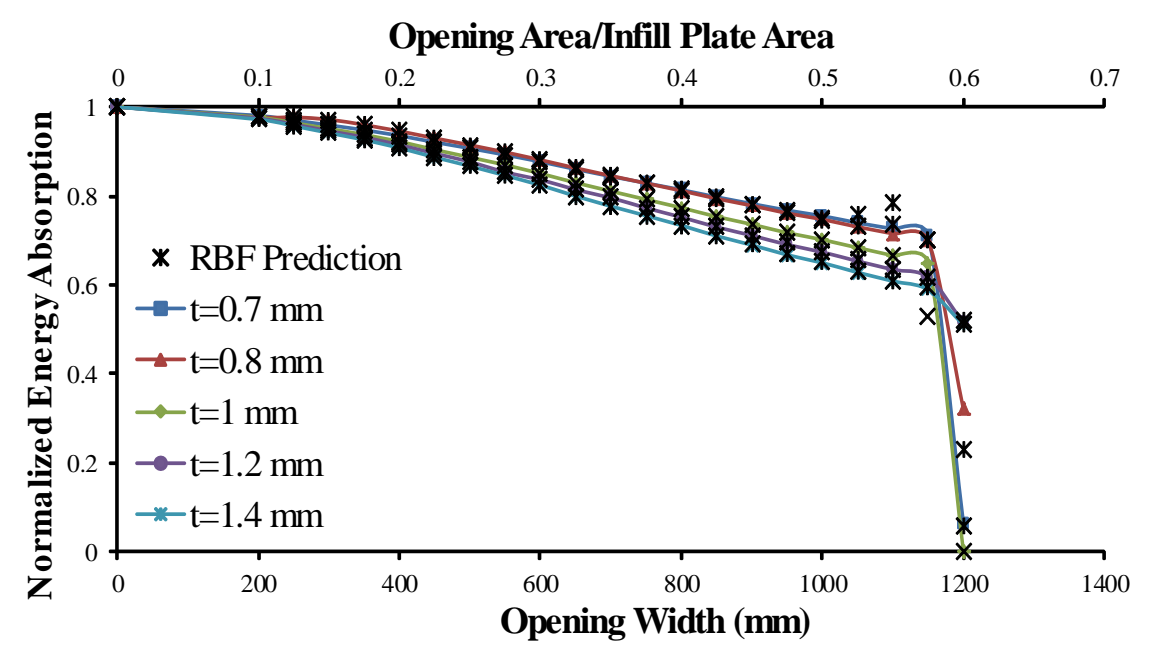

Figure 10. Real and predicted normalized absorbed energy values versus the various $\mathrm{A}_{o} / \mathrm{A}_{s}$. 


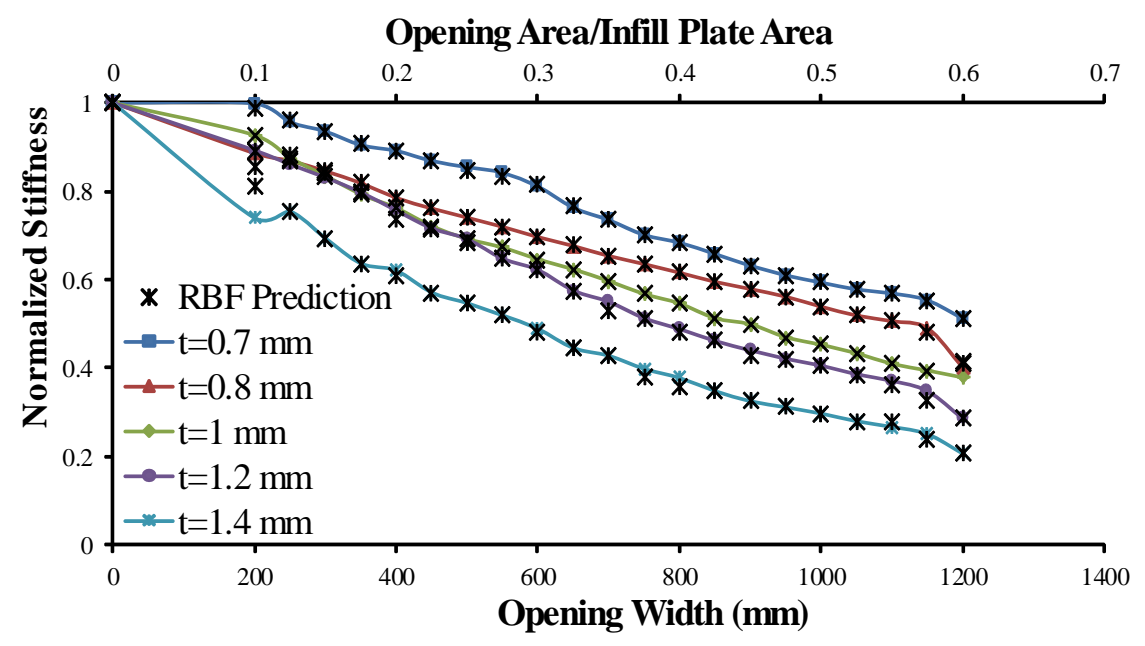

Figure 11. Real and predicted normalized stiffness values versus the various $A_{o} / A_{s}$.

\section{Conclusions}

Considering the increasing use of the steel plate shear wall as a lateral load-bearing system in high-rise buildings, investigating the behavior of this system is important. The opening in the infill plate of SPSW can be made due to functional and/or architectural purposes. The effect of opening existence along with the influence of opening area on the behavior of the SPSW needs to be understood. In this paper, 110 steel shear walls specimens were modeled and analyzed using the finite element method. The results were used to develop a simple, fast and accurate machine learning method, called $\mathrm{RBF}$, in order to estimate the seismic performance of the SPSWs. The result was normalized so that it can be used for any SPSW with arbitrary dimensions.

The outputs of the network are normalized ultimate load, absorbed energy, and stiffness. The results showed that the presence of rectangular openings decreases the load capacity, stiffness and, energy absorption of SPSWs. An opening with the ratio of opening area to infill-plate area, i.e., $\mathrm{A}_{o} / \mathrm{A}_{s}$, up to $15 \%$ will not have much impact on reducing the load capacity and energy absorption. The shear wall stiffness is dramatically affected by the thickness of the infill plate. The results show that locating an opening in the thicker infill plates will result in a further reduction in stiffness. In addition, the results indicated that the proposed neural network could precisely predict the effects of rectangular opening on the behavior of the steel shear walls.

Author Contributions: Conceptualization, M.J.M.; methodology, M.J.M., M.M.R., and A.S.; software, M.J.M.; validation, M.J.M.; formal analysis, M.J.M.; investigation, M.J.M., and A.S.; resources, M.J.M., M.M.R., and A.S.; data curation, M.J.M.; writing-original draft preparation, M.J.M.; writing-review and editing, M.J.M., A.S., and M.K.; visualization, X.X.; supervision, M.K.; funding acquisition, A.S., and M.K." All authors have read and agreed to the published version of the manuscript.

Funding: This research received no external funding.

Conflicts of Interest: The authors declare no conflict of interest.

\section{References}

1. Sitar, N.; Mikola, R.G.; Candia, G. Seismically Induced Lateral Earth Pressures on Retaining Structures and Basement Walls; Geotechnical Special Publication: Oakland, CA, USA, 2012; pp. 335-358.

2. Shabani, A.; Erfani, S. Seismic Performance Evaluation of SSMF with Simple Beam-Column Connections Under the Base Level. Int. J. Steel Struct. 2019, 20, 1-12. [CrossRef]

3. Shan, S.; Li, S.; Kose, M.M.; Sezen, H.; Wang, S. Effect of partial infill walls on collapse behavior of reinforced concrete frames. Eng. Struct. 2019, 197, 109377. [CrossRef]

4. Shan, S.; Li, S.; Wang, S.; Sezen, H.; Kose, M.M. Influence of masonry infill walls on fire-induced collapse mechanisms of steel frames. J. Constr. Steel Res. 2019, 155, 426-437. [CrossRef] 
5. Moradi, M.J.; Hariri-Ardebili, M.A. Developing a Library of Shear Walls Database and the Neural Network Based Predictive Meta-Model. Appl. Sci. 2019, 9, 2562. [CrossRef]

6. AISC. Resistance Factor Design Specification for Structural Steel Buildings; American Institute of Steel Construction: Chicago, IL, USA, 1999; Volume 1.

7. CAN, C. CSA-S16-01, Limit States Design of Steel Structures; Canadian Standards Association: Toronto, ON, Canada, 2001.

8. Timler, P. Economical design of steel plate shear walls from a consulting engineers perspective. In Proceedings of the 1999 North American Steel Construction Conference (NASCC), Toronto, ON, Canada, 10-12 May 1999; p. 36.

9. Sabouri-Ghomi, S.; Ahouri, E.; Sajadi, R.; Alavi, M.; Roufegarinejad, A.; Bradford, M. Stiffness and strength degradation of steel shear walls having an arbitrarily-located opening. J. Constr. Steel Res. 2012, 79, 91-100. [CrossRef]

10. Timler, P.A.; Kulak, G.L. Experimental Study of Steel Plate Shear Walls; Structural Engineering Report No. 114; Department of Civil Engineering, University of Alberta: Edmonton, AB, Canada, 1983.

11. Hajimirsadeghi, M.; Mirtaheri, M.; Zandi, A.; Hariri-Ardebili, M. Experimental cyclic test and failure modes of a full scale enhanced modular steel plate shear wall. Eng. Fail. Anal. 2019, 95, 283-288. [CrossRef]

12. Driver, R.G.; Kulak, G.L.; Kennedy, D.L.; Elwi, A.E. Cyclic test of four-story steel plate shear wall. J. Struct. Eng. 1998, 124, 112-120. [CrossRef]

13. Park, H.S.; Hong, K.; Seo, J.H. Drift design of steel-frame shear-wall systems for tall buildings. Struct. Des. Tall Build. 2002, 11, 35-49. [CrossRef]

14. Bypour, M.; Kioumarsi, B.; Kioumarsi, M. Investigation of Failure Mechanism of Thin Steel Plate Shear Wall in RC Frame. In Key Engineering Materials; Trans Tech Publication Ltd.: Zürich, Switzerland, 2019; Volume 803, pp. 314-321.

15. Bypour, M.; Gholhaki, M.; Kioumarsi, M.; Kioumarsi, B. Nonlinear analysis to investigate effect of connection type on behavior of steel plate shear wall in RC frame. Eng. Struct. 2019, 179, 611-624. [CrossRef]

16. Kioumarsi, B.; Gholhaki, M.; Kheyroddin, A.; Kioumarsi, M. Analytical study of building height effects over Steel Plate Shear Wall Behavior. Int. J. Eng. Technol. Innov. 2016, 6, 255.

17. Afshari, M.J.; Gholhaki, M. Shear strength degradation of steel plate shear walls with optional located opening. Arch. Civ. Mech. Eng. 2018, 18, 1547-1561. [CrossRef]

18. Behbahanifard, M.R.; Grondin, G.Y.; Elwi, A.E.A. Experimental and Numerical Investigation of Steel Plate Shear Walls; University of Alberta, Department of Civil and Environmental Engineering: Edmonton, AB, Canada, 2003.

19. Takahashi, Y.; Takemoto, Y.; Takeda, T.; Takagi, M. Experimental Study on Thin Steel Shear Walls and Particular Bracing under Alternative Horizontal Load; Preliminary Report; IABSE: Lisbon, Portugal, 1973; pp. 185-191.

20. Roberts, T.M.; Sabouri-Ghomi, S. Hysteretic characteristics of unstiffened perforated steel plate shear panels. Thin-Walled Struct. 1992, 14, 139-151. [CrossRef]

21. Deylami, A.; Daftari, H. Non-linear behavior of steel shear wall with large rectangular opening. In Proceedings of the 12th World Conference on Earthquake Engineering 2000, Auckland, New Zealand, 30 January-4 February 2000.

22. Vian, D.; Bruneau, M. Testing of Specially Steel Plate Shear Walls. In Proceedings of the 4th International Conference on Earthquake Engineering, Graz, Austria, 6-8 September 2006.

23. Pellegrino, C.; Maiorana, E.; Modena, C. Linear and non-linear behaviour of steel plates with circular and rectangular holes under shear loading. Thin-Walled Struct. 2009, 47, 607-616. [CrossRef]

24. Paik, J.K. Ultimate strength of perforated steel plates under edge shear loading. Thin-Walled Struct. 2007, 45, 301-306. [CrossRef]

25. Valizadeh, H.; Sheidaii, M.; Showkati, H. Experimental investigation on cyclic behavior of perforated steel plate shear walls. J. Constr. Steel Res. 2012, 70, 308-316. [CrossRef]

26. Alavi, E.; Nateghi, F. Experimental study on diagonally stiffened steel plate shear walls with central perforation. J. Constr. Steel Res. 2013, 89, 9-20. [CrossRef]

27. Bhowmick, A.K. Seismic behavior of steel plate shear walls with centrally placed circular perforations. Thin-Walled Struct. 2014, 75, 30-42. [CrossRef] 
28. Purba, R.; Bruneau, M. Seismic performance of steel plate shear walls considering two different design philosophies of infill plates. I: Deterioration model development. J. Struct. Eng. 2014, 141, 04014160. [CrossRef]

29. Khalilzadeh Vahidi, E.; Roshani, M. Prediction of load-carrying capacity in steel shear wall with opening using artificial neural network. J. Eng. 2016, 2016. [CrossRef]

30. Nassernia, S.; Showkati, H. Experimental study of opening effects on mid-span steel plate shear walls. J. Constr. Steel Res. 2017, 137, 8-18. [CrossRef]

31. Asteris, P.G.; Nikoo, M. Artificial bee colony-based neural network for the prediction of the fundamental period of infilled frame structures. Neural Comput. Appl. 2019, 31, 4837-4847. [CrossRef]

32. Asteris, P.G.; Armaghani, D.J.; Hatzigeorgiou, G.D.; Karayannis, C.G.; Pilakoutas, K. Predicting the shear strength of reinforced concrete beams using Artificial Neural Networks. Comput. Concr. 2019, 24, 469-488.

33. Asteris, P.G.; Plevris, V. Anisotropic masonry failure criterion using artificial neural networks. Neural Comput. Appl. 2017, 28, 2207-2229. [CrossRef]

34. Asteris, P.G.; Apostolopoulou, M.; Skentou, A.D.; Moropoulou, A. Application of artificial neural networks for the prediction of the compressive strength of cement-based mortars. Comput. Concr. 2019, 24, 329-345.

35. Asteris, P.G.; Mokos, V.G. Concrete compressive strength using artificial neural networks. Neural Comput. Appl. 2019, 1-20. [CrossRef]

36. Plevris, V.; Asteris, P.G. Modeling of masonry failure surface under biaxial compressive stress using Neural Networks. Constr. Build. Mater. 2014, 55, 447-461. [CrossRef]

37. Zhao, Z.; Ren, L. Failure criterion of concrete under triaxial stresses using neural networks. Comput. Civ. Infrastruct. Eng. 2002, 17, 68-73. [CrossRef]

38. Hossain, M.S.; Ong, Z.C.; Ismail, Z.; Noroozi, S.; Khoo, S.Y. Artificial neural networks for vibration based inverse parametric identifications: A review. Appl. Soft Comput. 2017, 52, 203-219. [CrossRef]

39. Sabouri-Ghomi, S.; Mamazizi, S. Experimental investigation on stiffened steel plate shear walls with two rectangular openings. Thin-Walled Struct. 2015, 86, 56-66. [CrossRef]

40. Abaqus, I. ABAQUS/Explicit User's Manual; Dassault Systèmes Simulia Corp.: Providence, RI, USA, 2002.

41. Roshani, S.; Roshani, S. Two-Section Impedance Transformer Design and Modeling for Power Amplifier Applications. Appl. Comput. Electromagn. Soc. J. 2017, 32, 1042-1047.

42. Roshani, G.H.; Roshani, S.; Nazemi, E.; Roshani, S. Online measuring density of oil products in annular regime of gas-liquid two phase flows. Measurement 2018, 129, 296-301. [CrossRef]

43. Yao, W.; Fang, J.; Zhao, P.; Liu, S.; Wen, J.; Wang, S. TCSC nonlinear adaptive damping controller design based on RBF neural network to enhance power system stability. J. Electr. Eng. Technol. 2013, 8, 252-261. [CrossRef]

44. Zirak, A.R.; Roshani, S. A Reduced Switch Voltage Stress Class E Power Amplifier Using Harmonic Control Network. Int. J. Adv. Comput. Sci. Appl. 2016, 7, 38-42.

45. Militkỳ, J. Fundamentals of soft models in textiles. In Soft Computing in Textile Engineering; Elsevier: Amsterdam, The Netherlands, 2011; pp. 45-102.

(C) 2020 by the authors. Licensee MDPI, Basel, Switzerland. This article is an open access article distributed under the terms and conditions of the Creative Commons Attribution (CC BY) license (http://creativecommons.org/licenses/by/4.0/). 